\title{
The airway: problems and predictions in 18,500 patients
}

\author{
D. Keith Rose MD FRCPC,* \\ Marsha M. Cohen MD FRCPC† $\$ \S$
}

The purpose of this study was to describe methods, risk factors, and outcomes of airway management in all patients (obstetrics excluded) attended by anaesthetists over 27 months. Preoperatively, anaesthetists recorded patient factors and assessed four airway characteristics. Methods of tracheal intubation and ease of direct laryngoscopy following general anaesthesia (easy, awkward, difficult) were noted. Factors predictive of poor outcome and the value of the preoperative airway examination were determined. For 18,205 patients following a direct laryngoscopy, $(G A)$, tracheal intubation was difficult $>2$ laryngoscopies) in $1.8 \%$ and awkward ( $\leq 2$ laryngoscopies) in $2.5 \%$. This approach was a failure in $0.3 \%$, and surgery was postponed in $0.05 \%$. However, an alternative approach to direct laryngoscopy, (GA) was the first choice in 353 patients. Risk factors for difficult tracheal intubation included male sex, age 40-59 yr and obesity $(P \leq 0.01)$. For direct laryngoscopy, $(G A)$, airway characteristics predictive of difficult tracheal intubation were decreased mouth opening (relative risk 10.3), shortened thyromental distance (9.7), poor visualization of the hypopharynx (4.5), and limited neck extension (3.2), any two (7.6) and more than two (9.4) $(P<0.01)$. For 1,856 patients $(10.0 \%)$ where at least one airway characteristic was abnormal, a direct laryngoscopy, (GA) resulted in $8.3 \%$ awkward and $6.0 \%$ difficult tracheal intubations.

\section{Key words}

AIRWAY: assessment;

INTUBATION: tracheal

From the Department of Anaesthesia, St. Michael's Hospital*; Clinical Epidemiology Unit, Sunnybrook Health Science Centre and The Institute for Clinical Evaluative Sciences, Toronto Ontario†; Department of Health Administrationt; Department of Anaesthesia, Sunnybrook Health Science Centre§; University of Toronto, Toronto, Ontario.

Supported by a grant from Physicians' Services Incorporated and by a National Health Scholar Award (Health and Welfare Canada) to Dr. Cohen.

Presented in part at the Canadian Anaesthetists' Society annual meeting in Toronto, Ontario, June 1992 and Halifax, Nova Scotia, June 1993.

Address correspondence to: Dr. Keith Rose, Department of Anaesthesia, St. Michael's Hospital, 30 Bond Street, Toronto, Ontario, Canada, M5B IW8.

Accepted for publication 26th Jamuary, 1994
For patients with no abnormal airway characteristics, tracheal intubation was easy in $96.3 \%$. Where tracheal intubation was difficult, $34.3 \%$ of patients had one or more abnormal airway characteristics preoperatively. Patients with difficult tracheal intubation had an increased rate of desaturation (<90\%), hypertension $>200 \mathrm{mmHg}$ ) and dental damage on induction of anaesthesia. It is concluded that difficult tracheal intubations occurred infrequently but were associated with increased morbidity. Patient factors and four physical airway characteristics were useful predictors but limited in identifying all problems.

Cette étude porte sur la description des méthodes, des facteurs de risque et sur les résultats de la gestion des voies aériennes chez tous les patients ('obstétrique exclue) suivis par des anesthésistes sur une période de 27 mois. A la période préopératoire, les anesthésistes enregistrent les facteurs propres aux patients et évaluent quatre caractéristiques de leur voies aériennes. On note les méthodes dintubation endotrachéale et le degré de facilité (facile, malaisée, difficile) de la laryngoscopie directe après l'anesthésie générale $(A G)$. Les facteurs prédictifs de résultats défavorables et la valeur prédictive de l'examen préopératoire des voies aériennes sont déterminés. Chez 18,205 patients, lintubation sous laryngoscopie directe $(A G)$ a été difficile $>2$ laryngoscopies) dans $1,8 \%$ et malaisée ( $\leq 2$ laryngoscopies) dans $2,5 \%$. Cette approche a échoué dans $0,3 \%$ et la chirurgie reportée dans $0,05 \%$. Cependant une alternative à la laryngoscopie directe $(A G)$ a constitué le premier choix chez 353 patients. Les facteurs de risque de lintubation difficile comprennent le sexe masculin, lâge de 40 à 59 ans, et l'obésité $(P \leq 0,01)$. Pour la laryngoscopie directe $(A G)$, les caractéristiques des voies aériennes prédictives d'une intubation difficile sont la réduction de l'ouverture buccale (risque relatif 10,30), la diminution de la distance thyromentonnière $(9,7)$, linsuffisance de la visualisation de l'hypopharynx $(4,5)$ et la limitation de lextension du cou (3,2), deux (7,6) ou plus de deux de celles-ci $(9,4)(P<0,01)$. Chez 1,856 patients $(10,0 \%)$, on trouve au moins une caractéristique anormale: chez ceux-ci la laryngoscopie directe $(A G)$ s'avère malaisée dans $8,3 \%$ et difficile chez $6,0 \%$ des cas. Pour les patients sans anomalies, lintubation est facile dans $96,3 \%$ des cas. Quand lintubation est difficile, $34,3 \%$ des patients ont au moins une caractéristique anormale en préopératoire. Les patients intubés difficilement présentent 
une désaturation $(<90 \%)$ plus fréquente, de l'hypotension $>200 \mathrm{~mm} \mathrm{Hg}$ ) et des dommages dentaires à linduction de l'anesthésie. En conclusion, les intubations trachéales difficiles surviennent peu fréquemment mais sont associées à une augmentation de la morbidité. Les facteurs propres aux patients et quatre caractéristiques des voies aériennes sont des facteurs prédictifs utiles mais sont insuffisants pour identifier tous les problèmes.

Successful and safe tracheal intubation with induction of anaesthesia should prevent morbidity and avoid the serious consequences of failure to establish the airway. ${ }^{1-4}$ Many different strategies and techniques to secure the airway have been described for both patients who are awake and those who are anaesthetized. ${ }^{5-12}$ Recent studies have described alternative methods to establish the airway following an unanticipated, difficult or failed tracheal intubation. ${ }^{13,14}$ As well, guidelines for the recognition and management of the difficult airway have recently been developed. ${ }^{15}$ For the preoperative identification of patients with potentially difficult airways, several classifications have been proposed. ${ }^{16-22}$

However, the various problems encountered when securing the airway and the morbidity during, or following, tracheal intubation have been poorly and incompletely defined in some studies. No reports have described the various methods of tracheal intubation used in large populations in the actual clinical setting, nor the outcome of different techniques and their associated difficulties. In some articles, the classifications suggested for detection of the abnormal airway have been complex. The predictability of individual or multiple abnormal physical airway characteristics has not been established in large numbers of patients.

To address these issues we studied all patients who were attended by an anaesthetist in the operating room (OR) over a 27 -mo period $(n=29,145)$ to determine: (i) the various techniques of anaesthesia and methods of airway management used in clinical practice and their failure rates; (ii) the types of alternative approaches used for tracheal intubation (other than a direct laryngoscopy following induction of general anaesthesia), their failure rates, and the characteristics of patients for whom these approaches were chosen; (iii) the ease/difficulty of all tracheal intubations following direct laryngoscopy and induction of general anaesthesia and patient, surgical, and anaesthetic factors which were associated with a difficult or awkward tracheal intubation; (iv) the value of the preoperative airway examination and the usefulness of four physical signs (mouth opening, neck flexion, thyromental distance, and visualization of the hypopharynx) in predicting the ease/difficulty of direct laryngoscopy,
(GA) or use of an alternative approach; and (v) other adverse outcomes associated with the methods of tracheal intubation or their ease/difficulty.

\section{Methods}

Following approval of the Hospital Human Ethics Committee, we prospectively collected data on all patients attended by anaesthetists in our operating room (January 1, 1991 through to March 31, 1993). In our hospital, obstetrical patients requiring general anaesthesia were few $(<1 \%$ of the entire study population) and since airway data were incomplete, these patients were not included. Before initiation of the study, variables were defined by the investigators (Appendix Tables I and II) and included the methods used for tracheal intubation, any problems with tracheal intubation, and the preoperative airway assessment which included four specific characteristics of the airway. This information was subsequently included on a newly revised double copy anaesthetic record. A tic-box format for each piece of information required was an integral part of the design of the revised record. All anaesthetists participated in the revision of the anaesthetic record and were aware of the preoperative characteristics to be documented before induction of anaesthesia and the outcomes to be recorded.

The airway examination, which was performed preoperatively, was assessed by the examination of four physical characteristics. If no limitations for all four characteristics were documented on the chart, the assessment was considered normal. Abnormal airway assessments were identified by the documentation of limitation in one or more of these physical characteristics. Records with incomplete or missing information on the four physical characteristics were evaluated separately from those with all four characteristics noted to determine the impact of missing preoperative documentation.

When direct laryngoscopy, (GA) was chosen, the anaesthetist recorded the ease of tracheal intubation (easy or difficult depending on the view at laryngoscopy) and the number of laryngoscopy attempts. Based on these two pieces of information, the outcome was classified into three categories: easy, awkward (tracheal intubation was recorded by the anaesthetist as difficult and insertion of the endotracheal tube was successful with one or two laryngoscopies), or difficult (recorded as difficult but more than two laryngoscopies required). Failure of any tracheal intubation method was noted by the anaesthetist on the record and subsequent methods necessary to secure the airway were documented. Due to lack of welldefined criteria for optimal intubating position, intensity of laryngeal neuromuscular relaxation, or laryngoscope size and type, no attempt was made to standardize these variables. 
In addition to information about the airway and tracheal intubation, preoperative demographic factors (e.g., age, sex), patient illnesses, current medications, anaesthetic techniques and drugs were also recorded on the anaesthetic record. Intraoperative and postoperative patient problems (e.g., cardiac and respiratory) were all specifically defined on the record, and the relevant patient outcomes are listed in Appendix Table III. Surgical procedures, coded by the International Classification of Diseases (Ninth Revision), were further classified into 18 major families. ${ }^{23}$

The carbon copies of all anaesthetic records were reviewed the day after surgery by a trained anaesthetic research nurse and a clinical anaesthetist to ensure accuracy and completeness. If relevant information was unclear or missing, wherever possible, data were added after direct consultation with the anaesthetist who was responsible for the intubation. All data were entered into a customized database programme and were analyzed using the Statistical Analysis System (SAS ${ }^{\circledR}$ version 6.04). ${ }^{24}$

The different anaesthetic techniques/approaches were first identified and for tracheal intubation cases, the initial methods chosen (direct laryngoscopy, (GA), or alternative approaches), their failure rate, and the subsequent methods used to secure the airway for failures were noted. For direct laryngoscopy, (GA), the resulting outcomes were determined (whether easy, awkward or difficult). If the ease/difficulty of tracheal intubation following direct laryngoscopy, (GA) was not recorded on the chart, then these patients were noted but omitted from further analysis ( $n=302-1.6 \%$ of all tracheal intubations).

Next, characteristics of the patients in the three groups (awkward tracheal intubation following general anaesthesia, difficult tracheal intubation following general anaesthesia, or alternative approach) were compared with patients in the easy tracheal intubation group following direct laryngoscopy, (GA). The factors (patient, surgical, and anaesthetic) which identified these patients were compared using the chi square or Fisher's exact test $(P<0.01)$.

It was determined if patients with specific abnormal airway characteristics were more likely to have had an awkward or difficult tracheal intubation or an alternative method as compared to patients with normal airway examinations. For each single airway characteristic, or multiples thereof (two and more than two), the proportions of cases where the tracheal intubation was easy, awkward, difficult, or an alternative approach were determined. These proportions were compared by the chi square or Fisher's exact test $(P<0.01)$. Comparisons between the group whose airway assessment was documented as normal preoperatively and the cases with incomplete or missing documentation on the airway were also performed.

The "specificity" (the ratio of those with a normal air- way examination and an easy tracheal intubation to all those with an easy tracheal intubation) and the "positive predictive value" (the ratio of those with a specific airway abnormality who had an awkward or difficult outcome or an alternative method to all those with that specific airway abnormality) were calculated. "Sensitivity" values (the ratio of the number of patients who were identified preoperatively with any abnormal airway characteristic who had a specific tracheal intubation problem to the total number of patients who had that tracheal intubation problem) were calculated for three categories: tracheal intubations which were awkward, tracheal intubations which were difficult following direct laryngoscopy, (GA), or initial choice of an alternative method.

A separate analysis was carried out for patients who had a direct laryngoscopy, (GA) to determine which of the individual or multiple airway characteristics best predicted a difficult tracheal intubation. The relative risk (and $99 \%$ confidence intervals) of having a difficult tracheal intubation, if a patient had an abnormal airway characteristic, compared with patients with four normal characteristics was calculated. If the relative risk was greater than one, an increased risk for difficult tracheal intubation was identified.

Finally, the frequencies of other adverse outcomes (desaturation, tachycardia etc.) were compared among patients who had either direct laryngoscopy, (GA) (easy, awkward, or difficult tracheal intubation) or an alternative method using the chi square or Fisher's exact test ( $P$ $<0.01)$.

\section{Results}

\section{Techniques for anaesthesia and airway management}

Tracheal intubation was attempted in 18,558 of 29,145 patients (Table I), and for tracheal intubation, anaesthetists chose direct laryngoscopy, (GA) $98.1 \%$ of the time. The failure rate was $0.3 \%$ for tracheal intubation performed using direct laryngoscopy, (GA). The failure rates for other techniques/methods was $4.7 \%$ for laryngeal mask, $0.9 \%$ for mask, $8.2 \%$ for regional technique and $0.6 \%$ for neurolept analgesia.

\section{Alternative approaches}

For those patients in whom tracheal intubation was attempted, an alternative approach was first used in 353 patients (1.9\% of patients whose tracheas were intubated) (Table II). Tracheal intubation with the assistance of a fibreoptic bronchoscope without general anaesthesia was the commonest approach. For 11 patients where the initial alternative approach failed, all second approaches (five fibreoptic, five direct laryngoscopy, and one retrograde) were successful without general anaesthesia. 
TABLE I Anaesthesia and airway management - initial methods and failures* in 29,145 consecutive patients over a 27 -month period

\begin{tabular}{lcccc}
\hline Initial technique/method & $\begin{array}{c}\text { Number of } \\
\text { patients }\end{array}$ & \% Total & $\begin{array}{c}\text { Number of } \\
\text { failures* }\end{array}$ & \% Failures. \\
\hline Intubated using direct laryngoscopy, (GA) & 18205 & 62.5 & 54 & 0.3 \\
Intubated using alternative approach $\dagger$ & 353 & 1.2 & 11 & 3.1 \\
& & & & \\
Laryngeal mask & 634 & 2.2 & 30 & 4.7 \\
Mask & 3367 & 11.6 & 30 & 0.9 \\
Endotracheal tube in situ & 781 & 2.7 & - & - \\
Regional technique & 839 & 2.9 & 69 & 8.2 \\
Neurolept analgesia & 4966 & 17.0 & $\underline{32}$ & $\underline{0.6}$ \\
Total patients & 29145 & & 226 & 0.8 \\
\hline
\end{tabular}

* Required use of a different anaesthetic/intubation technique to manage the airway or case cancelled - for regional or neurolept anaesthesia another anaesthetic technique was required.

$†$ Any method to intubate the trachea in a patient without general anaesthesia, and/or those involving fibreoptic, lightwand, retrograde placement and/or tracheostomy.

TABLE II Types of alternative approaches used for initial tracheal intubation $(n=353)$

\begin{tabular}{|c|c|c|c|}
\hline \multirow{2}{*}{$\begin{array}{l}\text { Initial } \\
\text { approach }\end{array}$} & \multirow[b]{2}{*}{$n$} & \multicolumn{2}{|c|}{ Failure* } \\
\hline & & $n$ & $\%$ \\
\hline \multicolumn{4}{|c|}{ With general anaesthesia } \\
\hline Blind nasal & 12 & 0 & 0 \\
\hline Fibreoptic & 4 & 0 & 0 \\
\hline Lightwand & 1 & 0 & 0 \\
\hline Tracheostomy & 1 & 0 & 0 \\
\hline \multicolumn{4}{|l|}{ Awake } \\
\hline Direct laryngoscopy & 32 & 2 & 6.3 \\
\hline Blind nasal & 20 & 4 & 20.0 \\
\hline Fibreoptic & 268 & 5 & 1.9 \\
\hline Retrograde & 2 & 0 & 0 \\
\hline Tracheostomy & 13 & 0 & 0 \\
\hline
\end{tabular}

*Failure - different approach or technique required.

Men and patients over $60 \mathrm{yr}$ were more likely to have received an alternative approach initially as were emergency cases and those whose ASA physical status score was three or more (Table III). Preexisting conditions and the surgical procedure were also associated with increased use of an alternative approach compared to patients whose initial approach was direct, laryngoscopy, (GA) and easy.

\section{Ease/difficulty of direct laryngoscopy, (GA)}

For the majority of patients where tracheal intubation was attempted by direct laryngoscopy following induction of anaesthesia, there were no problems with tracheal intubation (Table IV). There were 17,129 patients $(94.1 \%)$ whose tracheal intubation was recorded as easy. Tracheal intubation was noted to be awkward for 448 patients
(2.5\%), and difficult for 326 patients (1.8\%). Seventy-two patients $(0.4 \%)$ required more than three laryngoscopies. Information about the laryngoscopy was missing on 302 patients. For patients in the awkward group, an endotracheal tube was successfully inserted in every case. For the 326 patients in whom tracheal intubation was recorded as difficult, tracheal intubation was successful in 272 with direct laryngoscopy, (GA) with more than two laryngoscopies. However, this approach failed in 54 patients $(0.3 \%$ of all tracheal intubations) and required a different method to secure the airway, a new anaesthetic plan, or postponement of the surgical procedure. Twenty-five patients were continued under general anaesthesia, six with mask anaesthesia. In two, intubation was achieved using a blind nasal method, two required tracheostomy, and in 15 fibreoptic assistance was used to insert the endotracheal tube. For the remaining 29 patients general anaesthesia was discontinued. For one patient a neurolept analgesic technique was chosen and the surgery completed, and for another the airway was secured using a guidewire and a retrograde method. A fibreoptic bronchoscope was used successfully to secure the airway for 17 patients but for ten others $(0.05 \%$ of all tracheal intubations) after multiple laryngoscopy attempts and use of alternative approaches when appropriate, the proposed surgery was cancelled. These ten patients were returned to the operating room at a later date. None of these 54 patients, in whom tracheal intubation by direct laryngoscopy, (GA) failed, required transtracheal ventilation. However, in two, increasing difficulty with ventilation was documented prompting alternative airway management. During tracheal intubation attempts, these two patients were noted to have blood in the airway and oxygen saturation below $90 \%$. Both patients were awakened and ventilatory failure avoided. There were no patients in 
TABLE III Patient, surgical and anaesthetic factors associated with method and outcome of tracheal intubation

\begin{tabular}{|c|c|c|c|c|}
\hline \multirow[b]{2}{*}{ Factor } & \multicolumn{3}{|c|}{ Direct Laryngoscopy, $(G A)$} & \multirow[b]{2}{*}{$\begin{array}{l}\text { Alternative approach } \\
(n=353) \\
\%\end{array}$} \\
\hline & $\begin{array}{l}\text { Easy } \\
(n=17,129) \\
\%\end{array}$ & $\begin{array}{l}\text { Awkward } \\
(n=448) \\
\%\end{array}$ & $\begin{array}{l}\text { Difficult } \\
(n=326) \\
\%\end{array}$ & \\
\hline Male sex & 41.6 & $52.2^{*}$ & $56.4^{*}$ & $65.7^{*}$ \\
\hline Age $\geq 60 \mathrm{yr}$ & 28.0 & 29.9 & 31.9 & $34.3^{*}$ \\
\hline Age $40-59$ yr & 30.2 & $42.9^{*}$ & $44.5^{*}$ & 32.6 \\
\hline Age $<40 \mathrm{yr}$ & 41.8 & $27.2^{*}$ & $23.6^{*}$ & $33.1^{*}$ \\
\hline ASA $3 / 4$ & 22.8 & 26.0 & $31.1^{*}$ & $47.3^{*}$ \\
\hline Emergency & 10.3 & 9.8 & 8.6 & $21.2^{*}$ \\
\hline Overweight $\left(\sigma^{x}>120 \mathrm{~kg},+9>100 \mathrm{~kg}\right)$ & 2.4 & $4.9^{*}$ & $5.5^{*}$ & 4.2 \\
\hline Diabetics using insulin & 2.2 & 2.6 & 3.5 & 1.2 \\
\hline Neuromuscular disease & 1.8 & 2.1 & 2.8 & $9.4^{*}$ \\
\hline Rheumatoid arthritis & 0.6 & 0.7 & 0.6 & $4.0^{*}$ \\
\hline Spinal procedure & 4.1 & 4.7 & 6.7 & $22.9^{*}$ \\
\hline Open heart procedure & 7.5 & 8.7 & 9.8 & $1.7^{*}$ \\
\hline Head and neck procedure & 3.8 & 4.9 & 4.3 & $11.0^{*}$ \\
\hline $\begin{array}{l}\text { Nondepolarizing relaxant for tracheal } \\
\text { intubation }\end{array}$ & 18.4 & 16.9 & 19.6 & N/A \\
\hline
\end{tabular}

Each patient group (awkward, difficult, and alternative approach) was compared to those who had an easy tracheal intubation following a direct laryngoscopy, (GA).

$* P<0.01$ different from easy - direct laryngoscopy (GA).

TABLE IV Ease/difficulty of direct laryngoscopy, (GA), $(n=18,205)$

\begin{tabular}{lll}
\hline Type/ease & & $\begin{array}{l}\text { \% of direct } \\
\text { laryngascopies, }(G A)\end{array}$ \\
\hline Direct laryngoscopy, (GA) & & \\
Easy tracheal intubation & 17129 & 94.1 \\
Awkward tracheal intubation $\dagger$ & 448 & 2.5 \\
Difficult tracheal intubation* (failed) & $326(54)$ & $1.8(0.3)$ \\
Easy missing & 302 & 1.6 \\
\hline
\end{tabular}

* Difficult tracheal intubation $>2$ laryngoscopies.

$\nmid$ Recorded as difficult but $\leq 2$ laryngoscopies.

whom both tracheal intubation and ventilation were impossible.

Preoperative patient and surgical factors which were associated with the various methods and outcomes are noted in Table III. Compared with patients whose intubation was easy, patients in whom tracheal intubation was awkward or difficult were more likely to be male, $40-59 \mathrm{yr}$ of age and overweight (males $>120 \mathrm{~kg}$, females $>100 \mathrm{~kg}$ ). Having insulin-dependent diabetes was not a factor for problems related to tracheal intubation. Nondepolarizing muscle relaxants (pancuronium, atracurium or vecuronium) were used alone to facilitate tracheal intubation in $18.4 \%$ of the patients and succinylcholine in 79.7\% who were anaesthetized and whose tracheas were intubated by direct laryngoscopy, (GA). Choice of muscle relaxants was not related to difficult or awkward tracheal intubation. In eight of the 54 patients in whom tracheal intubation by direct laryngoscopy, (GA) was a failure, nondepolarizing muscle relaxant drugs had been used to facilitate tracheal intubation; however, tracheal intubation was successful by a second and alternative method.

\section{The preoperative airway examination and prediction of the outcome of tracheal intubation}

The relationship of the airway examination and the method or outcome of tracheal intubation is shown in Table V. Most patients had a normal preoperative airway examination, but documentation was incomplete or missing in about a third of patients. The most common single abnormalities noted were restricted neck movement (3.0\%) and decreased visualization of the hypopharynx (2.2\%). Limited mouth opening was a characteristic of only 93 patients $(0.5 \%)$. Two abnormal characteristics were noted in $2.2 \%$ of all patients, the most common being restricted neck movement and decreased visualization of the hypopharynx. For each single or multiple abnormal preoperative characteristic listed in Table V, the rate of an awkward or difficult tracheal intubation following direct laryngoscopy, (GA) or choice of an alternative method was higher than if the airway examination was documented as completely normal. For example, with four normal characteristics documented preoperatively, $1.3 \%$ of patients had a difficult tracheal intubation, compared with $10.6 \%$ if the thyromental distance was less than three fingers. Conversely, the likelihood of an easy 
TABLE V Relationship of preoperative airway exam by method and outcome of tracheal intubation

\begin{tabular}{|c|c|c|c|c|c|c|c|c|}
\hline \multirow{3}{*}{$\begin{array}{l}\text { Preoperative airway examination } \\
\text { (total } n \text { ) }\end{array}$} & \multicolumn{6}{|c|}{ Direct laryngoscopy, $(G A)$ A } & & \\
\hline & \multicolumn{2}{|l|}{ Easy } & \multicolumn{2}{|c|}{ Awkward } & \multicolumn{2}{|c|}{ Difficult } & \multicolumn{2}{|c|}{ Alternative } \\
\hline & $n$ & Rate $(\%)$ & $n$ & Rate (\%) & $n$ & Rate (\%) & $n$ & Rate (\%) \\
\hline Normal (8953) & 8523 & 95.2 & 164 & 1.8 & 113 & 1.3 & 58 & 0.6 \\
\hline Documentation incomplete ( 3153 ) & 2967 & 94.1 & 58 & 1.8 & 53 & 1.7 & 13 & 0.4 \\
\hline Documentation missing (4596) & 4326 & 94.1 & 71 & 1.5 & 48 & 1.0 & 46 & 1.0 \\
\hline IMO only (93) & 58 & $62.4^{*}$ & 8 & $8.6 \dagger$ & 9 & $9.7 \ddagger$ & 16 & $17.2 \S$ \\
\hline (Neck only (556) & 418 & $75.1^{*}$ & 35 & $6.3+$ & 18 & $3.2+$ & 74 & $13.3 \S$ \\
\hline ITM only $(265)$ & 194 & $73.2^{*}$ & 30 & $11.3 \dagger$ & 28 & $10.6 t$ & 7 & 2.68 \\
\hline IVision hypopharynx (406) & 332 & $81.8^{*}$ & 27 & $6.7 \dagger$ & 21 & $5.2 \ddagger$ & 15 & $3.7 \S$ \\
\hline 2 Abnormalities (409) & 254 & $62.1^{*}$ & 42 & $10.3 \dagger$ & 28 & $6.8 t$ & 77 & $18.8 \S$ \\
\hline$\geq 3$ Abnormalities (127) & 57 & $44.9^{*}$ & 13 & $10.2 \dagger$ & 8 & $6.3 \ddagger$ & 47 & $37.0 \S$ \\
\hline All $(18558)$ & 17129 & & 448 & & 326 & & 353 & \\
\hline
\end{tabular}

$* P<0.01$ different from the outcome of an easy tracheal intubation if the airway examination was documented as completely normal.

$\dagger P<0.01$ different from the outcome of an awkward tracheal intubation if the airway examination was documented as completely normal.

$\ddagger P<0.01$ different from the outcome of a difficult tracheal intubation if the airway examination was documented as completely normal.

$\S P<0.01$ different from the alternative approach if the airway examination wsa documented as completely normal

ףExcludes 302 patients in whom ease/difficulty of laryngoscopy was missing.

tracheal intubation following induction of anaesthesia was less with any of the categories of abnormal airway examination. The chance of an easy tracheal intubation with four normal characteristics was $95.2 \%$, but if the mouth opening was limited, only $62.4 \%$ had an easy intubation.

The decision to proceed with an alternative approach initially, based on the preoperative airway characteristics was most likely with $\geq 3$ abnormalities $(37.0 \%$ of these patients had an alternative approach) and least likely if the thyromental distance was decreased $(2.6 \%)$ or the view of the hypopharynx was limited (3.7\%). Those with incomplete or missing documentation were no more likely to have an easy, awkward or difficult outcome or an alternative method used than those whose airway examination had complete documentation of four normal characteristics.

The relationship between the preoperative airway examination and the use of alternative methods and outcomes is summanized in the Figure. If no abnormality was documented ( $n=16,702$ or $90.0 \%$ ), for direct laryngoscopy, (GA), $96.3 \%$ of patients had an easy tracheal intubation (the specificity if all four airway characteristics were normal). For $1.7 \%$ of patients tracheal intubation was awkward and for $1.3 \%$ tracheal intubation was difficult. For 117 patients $(0.7 \%)$, an alternative approach was chosen even though the four characteristics examined in our study were normal.

For the $10 \%$ of patients $(1,856)$ who had an abnormal examination, $73.0 \%$ of patients had an easy tracheal intubation with direct laryngoscopy, (GA). This was fewer

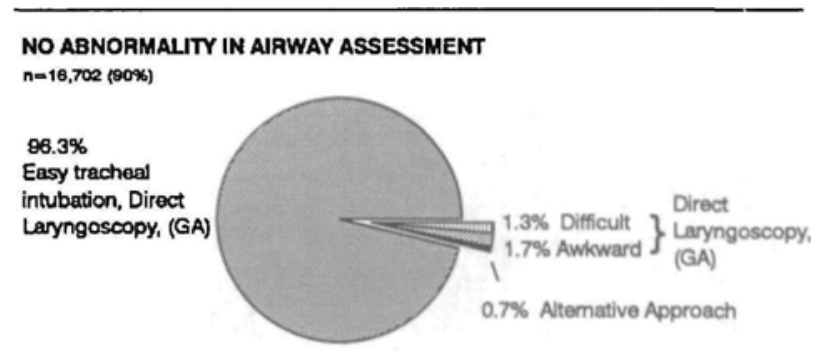

ABNORMAL AIRWAY ASSESSMENT

$n=1,856(10 \%)$

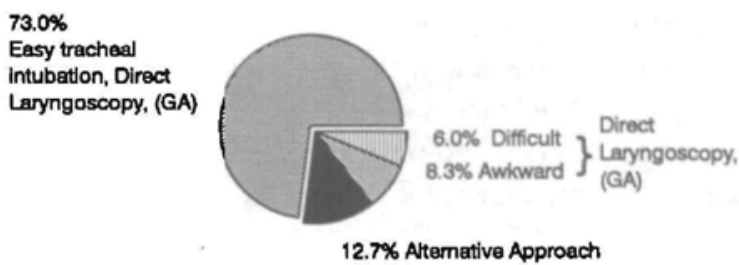

FIGURE Airway assessment - intubation method, and outcome in 18,588 patients

$(P<0.01)$ than those in whom preoperative examination was normal. For those identified preoperatively as abnormal, an alternative approach was used in 236 patients $(12.7 \%)$, and following direct laryngoscopy after general anaesthesia, 155 were awkward $(8.3 \%)$ and 112 were difficult $(6.0 \%)$ (positive predictive values). 
TABLE VI Prediction of difficult tracheal intubation $(>2$ laryngoscopies) by the preoperative airway examination

\begin{tabular}{lll}
\hline Airway examination & Relative risk & $\begin{array}{l}\text { Confidence interval } \\
(P<0.01)\end{array}$ \\
\hline IMO only & 10.3 & $3.5-30.5$ \\
INeck only & 3.2 & $1.7-6.0$ \\
ITM only & 9.7 & $5.6-16.5$ \\
IVisualization of hypopharynx & 4.5 & $2.5-8.3$ \\
2 Abnormalities & 7.6 & $4.4-12.4$ \\
$\geq 3$ Abnormalities & 9.4 & $3.8-23.3$ \\
& & \\
Any abnormality & 6.0 & $4.7-8.4$ \\
\hline
\end{tabular}

The proportion of specific airway problems which were identified preoperatively by any one of the four characteristics (sensitivity), was $66.9 \%$ for choice of alternative method; $34.6 \%$ for awkward tracheal intubation; and 34.3\% for difficult tracheal intubation. For those in whom surgery was cancelled due to difficult tracheal intubation $(n=10)$, only one had any abnormal characteristics identified preoperatively.

For patients who had other anaesthetic and airway techniques (Table I), the percentages of patients with abnormal airway characteristics were similar to those whose tracheas were intubated (e.g., laryngeal mask $8.4 \%$, regional technique $10.6 \%$ ) (data not shown). The use of nondepolarizing muscle relaxant agents for relaxation with tracheal intubation was similar in those who had normal characteristics and those who had one or more abnormal characteristics ( $18.1 \%$ versus $20.4 \%$ ).

The relative risk (RR) of airway characteristics which were most helpful in identifying a difficult tracheal intubation following induction of general anaesthesia are noted in Table VI. The best preoperative predictors for difficulty of tracheal intubation were decreased mouth opening $(R R=10.3)$, decreased thyromental distance $(R R=9.7)$ and the finding of three or more abnormal characteristics $(R R=9.4)$. Of the possible combinations for two abnormalities, four were significant (restricted neck movement in combination with mouth opening (RR $=10.9)$, decreased thyromental distance $(R R=8.5)$, decreased visualization of the hypopharynx $(R R=9.0$ ), and decreased thyromental distance and visualization of the hypopharynx $(R R=8.1)$. The single characteristics, decreased neck mobility and decreased visualization of the hypopharynx, were also significant predictors but had lower relative risks.

\section{Patient outcomes associated with method/outcome}

Other intraoperative and postoperative adverse outcomes according to the outcome or method of tracheal intubation are noted in Table VII. For those patients in whom tracheal intubation was awkward or difficult, there was a higher incidence of desaturation and oesophageal intubation during the induction period compared with patients who had an easy tracheal intubation. The rate of hypertension during induction of anaesthesia was higher in those who had a difficult tracheal intubation. Patients who had an initial alternative approach had higher rates of tachycardia and hypertension at induction and were more likely to arrive in the Post Anaesthetic Care Unit (PACU) with an endotracheal tube in place. The unexpected ICU admission rate either from the OR or the PACU was higher for patients who had an alternative approach or a difficult tracheal intubation. Unexpected ICU admissions following difficult tracheal intubation (five of six), and use of an alternative approach (three of four) were due to upper airway and respiratory problems, secondary to the airway management.

\section{Discussion}

The management of the airway with induction of anaesthesia is the primary and unique responsibility of the anaesthetist. Disastrous outcomes with failed or difficult tracheal intubation following the induction of general anaesthesia are well-known to anaesthetists. Tiret, in a prospective study from France, noted 16 severe complications (fatal or life threatening accidents or with severe sequelae) due to tracheal intubation in 198,000 anaesthetics. ${ }^{25}$ In Canada, a review of claims for obstetrical cases documented seven disastrous outcomes ${ }^{26}$ and in England, failure to intubate the trachea was one of the major causes of maternal mortality ( 8 of 22 deaths from 1979-1981). ${ }^{27}$ A study of malpractice suits in the Closed Claim study revealed that the median cost of settlement was $\$ 200,000$ when a life-threatening adverse outcome was associated with a respiratory event intraoperatively. ${ }^{1}$ Reports of other injuries following difficult tracheal intubation included dental injuries, oesophageal trauma, laryngeal damage, and hoarseness. ${ }^{28-32}$

The reported rate of difficult tracheal intubation depends on the definition chosen. Definitions used have included failure to intubate, ${ }^{33}$ more than two laryngoscopies, ${ }^{34}$ more than three attempts to pass the endotracheal tube or longer than ten minutes, ${ }^{15}$ or a poor view of the vocal cords on direct laryngoscopy. ${ }^{35}$ For the view at laryngoscopy, a frequently used definition, the relationship with the number of laryngoscopies, the number of tracheal intubation attempts and the degree of postoperative morbidity has not been clearly defined. There has been wide variation between studies and individual anaesthetists in the reporting of the view at laryngoscopy due to differences in mitigating factors (e.g., cricoid pressure, head position, degree of muscle relaxation and type or size of laryngoscope blade). ${ }^{7,19}$ Our 
TABLE VII Patient outcomes by method and ease of tracheal intubation

\begin{tabular}{|c|c|c|c|c|}
\hline \multirow[b]{2}{*}{ Problem } & \multicolumn{3}{|c|}{ Direct Laryngoscopy, (GA) } & \multirow[b]{2}{*}{$\begin{array}{l}\text { Alternative approach } \\
(n=353) \\
\%\end{array}$} \\
\hline & $\begin{array}{l}\text { Easy } \\
(n=17,129) \\
\%\end{array}$ & $\begin{array}{l}\text { Awkward } \\
(n=448) \\
\%\end{array}$ & $\begin{array}{l}\text { Difficult } \\
(n=326) \\
\%\end{array}$ & \\
\hline \multicolumn{5}{|l|}{ Operating Room } \\
\hline Desaturation on induction & 0.3 & $1.3^{*}$ & $1.8^{*}$ & 0.8 \\
\hline Tachycardia on induction & 1.5 & 1.3 & 2.8 & $5.4^{*}$ \\
\hline Hypertension on induction & 1.0 & 1.6 & $2.8^{*}$ & $2.6^{*}$ \\
\hline Oesophageal intubation & 0.3 & $3.3^{*}$ & $10.1^{*}$ & 0.8 \\
\hline Dental damage & 0.04 & 0 & $1.2^{*}$ & 0.3 \\
\hline \multicolumn{5}{|l|}{ Post-anaesthetic care unit } \\
\hline Arrive intubated & 1.9 & 3.3 & 4.0 & $9.8^{*}$ \\
\hline Nausea and vomiting & 11.2 & 14.0 & 10.5 & $6.0^{*}$ \\
\hline Unexpected ICU admission (OR or PACU) & 0.3 & 0.9 & $1.8^{*}$ & $1.1^{*}$ \\
\hline
\end{tabular}

$\%$ - the percentage of patients in each group who had the adverse outcome.

$* P<0.01$ different from easy direct laryngoscopy, (GA)

definition of difficulty (greater than two laryngoscopy attempts) was based on studies from otolaryngology, as well as ease of use. ${ }^{34}$ Samsun and Young found in $0.04 \%$ of 13,380 surgical patients, tracheal intubation was impossible. ${ }^{33}$ This figure corresponds to the ten patients $(0.05 \%)$ in our series in whom surgery was postponed. In another study of 751 randomly selected patients, the number experiencing poor laryngoscopic view (only epiglottis visible) was higher at $1.8 \% .^{20}$ Mallampati noted a frequency of an inability to expose the epiglottis in $4.3 \%$ of 210 consecutive patients. ${ }^{17}$

Various alternative methods, other than the usual direct laryngoscopy, (GA) approach have been described to achieve successful placement of an endotracheal tube without undue patient trauma. ${ }^{10-12,36-40}$ Although these methods have all been used for isolated cases, their rate of use in routine clinical practice has not been described. Many of these alternative methods and their failure rate depend on the equipment available and the expertise of the personnel at different institutions. The use of alternative approaches at our hospital was uncommon (1.9\% of all tracheal intubations). Since a fibreoptic bronchoscope was immediately available in the operating room, it was the most common alternative approach used. Also, when an alternative approach was chosen as initial management, $95 \%$ of patients remained awake during the insertion of the endotracheal tube. It has been demonstrated that airway structures are more difficult to visualize after paralysis. ${ }^{41}$ Fibreoptic tracheal intubation was the method of choice following a failed direct tracheal intubation attempt with general anaesthesia, but at this time only half the patients were awakened from general anaesthesia. The laryngeal mask was not used as an aid for tracheal in- tubation during the study period. This low frequency of alternative methods highlights the problem of learning new techniques due to the very limited number of patients who require alternative methods. One successful study on the acquisition of fibreoptic skills by anaesthetic trainees showed that new teaching strategies (use of simulators) resulted in an improvement in the rate of successful intubations..$^{42}$ Some centres have used practical workshops to introduce and improve the success rate of fibreoptic intubation. ${ }^{43}$

Although algorithms are available, the exact timing or the reasons to discontinue the initial tracheal intubation method after repeated laryngoscopies have not been clearly established. ${ }^{3,13}$ The failure rate of 54 in 18,205 patients $(0.3 \%)$ following direct laryngoscopy, $(\mathrm{GA})$ in this study was higher than the rates reported in some studies. ${ }^{3,44,45}$ This strategy may have reflected a preference to discontinue attempts at an early time and proceed to alternative management prior to significant airway trauma. This decision is based on multiple factors which include the urgency of the procedure, the initial view at laryngoscopy, the availability of both experienced personnel and equipment, and the expertise of the anaesthetist with direct laryngoscopy or alternative strategies. The use of a nondepolarizing muscle relaxant agent limits the choices for alternative strategies if a difficult tracheal intubation is encountered.

Risk factors for difficult tracheal intubation with predictive value identified in previous studies included obesity or short neck, dental structure, and diabetes as well as physical characteristics identified by the preoperative examination. ${ }^{44,46}$ Our study identified males, patients $40-59$ $\mathrm{yr}$ of age, and obese patients at risk for a difficult 
or awkward tracheal intubation following direct laryngoscopy, (GA). Patients $<40$ yr were at lower risk of tracheal intubation problems. The explanation for these age-related findings may have involved preexisting patient illness, reasons for the operation, or dental patterns none of which were included in this study. These few associated findings emphasize the lack of identifiable patient and surgical factors in predicting awkward or difficult tracheal intubation. However, for the choice of alternative approach, the type and urgency of the surgical procedure as well as patient history of neuromuscular disease, rheumatoid arthritis or ASA III and IV physical status were additional factors. More frequent use of alternative approaches in the emergency situation may have reflected the anaesthetist's concern for the hazards of airway management after induction of general anaesthesia in this group of patients. It was not surprising that spine and head and neck procedures, where surgery was planned for known airway problems (e.g., unstable cervical fractures and oral and laryngeal tumours) have a higher incidence of an alternative approach.

This study highlights the concern about incomplete documentation on the anaesthetic record. A crucial piece of information missing from many anaesthetic records was the documentation of the four signs of the preoperative airway evaluation. Documentation was absent in $24.8 \%$ of records, and in another $17.0 \%$ of records it was incomplete. However, the rate of difficult or awkward tracheal intubation with direct laryngoscopy, (GA) or alternative approach was not different from those recorded as completely normal. This lack of documentation may have reflected a failure to record normal findings rather than a failure to examine the airway. However, only with careful and routine preoperative airway assessments will anaesthetists be able to identify subtle limitations which can prove disastrous during tracheal intubation. We also recognize that accurate documentation is a sine qua non for quality care in anaesthesia.

Clinical trials have outlined preoperative airway assessment plans to aid the anaesthetist. Limited mouth opening, caused by pain or fixed restriction of the temporomandibular joint has been shown to influence the method or difficulty of tracheal intubation. ${ }^{47}$ Limitation of neck extension that results from decreased atlantoocciptal movement has been difficult to quantitate. In one study, $x$-ray criteria for atlanto-occipital extension were useful in predicting problems with laryngoscopy. ${ }^{48}$ In another small group of selected patients, if the atlantooccipital distance estimated by the angle transversed by the maxillary teeth when extending the neck from the neutral position was less than one-third of the normal $35^{\circ}$, difficulty occurred. ${ }^{16} \mathrm{~A}$ more recent study found that if the change in distance between the mandibular tip and the sternal notch in the neutral and extension position was less than $5 \mathrm{~cm}$, the laryngoscopic view was compromised ${ }^{49}$ Several variables (e.g., degree of neck extension during the measurement, length of mandible, and position of the larynx) can influence thyromental distance. It has been suggested that standardization or identification of each of these individual anatomical variables may improve predictability of this characteristic. ${ }^{50} \mathrm{Mal}-$ lampati's original preoperative airway classification system, Grade I-III, was based only on the ability to visualize the hypopharynx in the awake upright position with the tongue protruded. ${ }^{17}$ Fifteen of their 210 patients examined were noted to be Class III preoperatively, and in 14 out of these 15 patients the laryngoscopy view of the vocal cords was limited.

If more than one test was used preoperatively and multiple tests were abnormal, the likelihood of poor visualization of the larynx at direct laryngoscopy has been shown. ${ }^{16,19,51}$ The Wilson Risk Sum Criteria scored multiple variables (weight, head and neck movement, jaw movement, receding mandible, and buck teeth) from 0 (normal) to $\geq 2$ (severe). ${ }^{19} \mathrm{~A}$ total of 2 or more was predictive of poor visualization with laryngoscopy. A further study comparing the effectiveness of the Mallampati system for a single characteristic and Wilson's system based on multiple parameters was done prospectively in 651 patients. ${ }^{20}$ With both assessments plans, only $42 \%$ of patients with restricted view of the larynx were identified preoperatively, which is similar to our sensitivity value for difficult intubation (34.3\%). Our study agreed that multiple indicators were important in the decision to proceed with an initial alternative approach or in the difficulties encountered during the direct laryngoscopy, (GA).

Other factors (poor dentition, position of upper incisors, lower airway abnormalities, surgical distortion, and previous history of difficult tracheal intubation) were not included in our study: These additional factors could have accounted for the patients who had an alternative approach when all four physical characteristics were documented as normal. Studies which assess the role of these additional and multiple factors could help the anaesthetist identify those at risk and potentially reduce the rate and the problems of difficult or failed tracheal intubations. A simple scoring system based on past history, dentition and multiple objective measurements of physical characteristics could be developed.

Caution has been expressed by several evaluators that the airway assessment of physical characteristics should include examination of the patient in a specific position without phonation, and that not all assessments which were originally classified as abnormal have been reproducible. ${ }^{22,52}$ This was likely a limitation to our study, as many anaesthetists and anaesthesia residents documented 
the four characteristics used in our preoperative evaluation. Similarly, the precision of measurement and adherence to suggested protocols during these measurements were not enforced. We did not document the reason for limited mouth opening nor did we define precise criteria for neck extension. Only a "yes" or "no" response for adequate visualization of the hypopharynx and not the Mallampati classification was required, and we did not emphasize that thyromental distance was most reliable if measured in extension. Not all patients had documentation of a complete airway examination before tracheal intubation. Therefore, although our study was successful in identifying four physical characteristics and the presence of multiple physical characteristics as major risk factors, the low sensitivity score and low positive predictive value for each of the abnormal characteristics may be due in part to these imprecise measurement techniques and missing documentation. However, our study reflected the current reality of the actual practice setting and the measurements that the practising clinician performed.

In future studies, it may be difficult to compare the incidence of difficult tracheal intubation and the sensitivity and positive predictive values of preoperative assessments. If alternative airway management strategies for patients with abnormal characteristics replace direct laryngoscopy, (GA), the actual degree of difficulty may be unknown if not confirmed by direct laryngoscopy. When multiple characteristics in addition to those from this study are used to identify problems, the comparison of positive predictive values may be more complex.

Our study has noted an increase in morbidity in those patients who have an awkward or difficult tracheal intubation. These events were not common but included desaturation and hypertension on induction, oesophageal intubation, and dental injury. These patients also had a higher rate of unexpected ICU admission. Ten patients had their surgery postponed and required longer lengths of hospital stay before the definitive surgical procedures.

In summary, this survey has determined the rate of alternative approaches and awkward and difficult tracheal intubations following induction of general anaesthesia in a clinical setting. For those 18,558 patients who required a tracheal intubation, $1,127(6.1 \%)$ did not have an easy tracheal intubation. Only sex, age, and weight were helpful in identifying risk of difficult tracheal intubation. Although the four airway characteristics examined in this study, both single and multiple, helped to predict airway problems, their usefulness was limited by poor sensitivity and positive predictive values.

\section{Acknowledgement}

The authors wish to thank all the anaesthetists and anaesthesia residents at St. Michael's Hospital, University of
Toronto who assisted in the data collection for this study, Anita Low for the daily review of this data, Mary Tan for the data entry and statistical compilation and Kerry McClenaghan for preparation of the manuscript.

\section{Appendices}

TABLE 1 Tracheal intubation techniques and outcomes

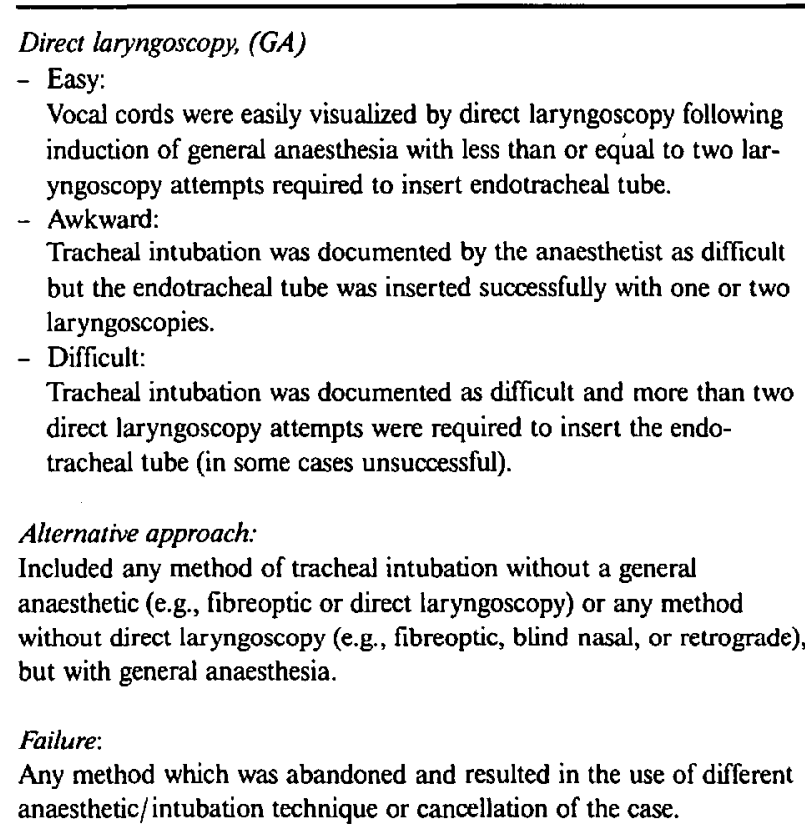

TABLE II Preoperative airway examination characteristics

Normal

By physical examination and documentation on the anaesthetic record, mouth opening $\geq 2$ fingers, full neck movement, thyromental distance $\geq 3$ fingers, and hypopharynx (uvula) well-visualized.

Documentation incomplete:

One or more of the physical findings (mouth opening, neck movement, thyromental distance, or visualization of the hypopharynx) were noted on the record as normal, but for one or more of the other characteristics there were no recordings.

- Documentation missing:

No documentation of preoperative airway examination, but also no indication of abnormalities or anticipated problems.

Abnormal characteristics

\begin{tabular}{|c|c|}
\hline I MO & Mouth opening $<2$ fingers. \\
\hline I Neck movement & Limited range of flexion and/or extension \\
\hline I TM distance & Thyromental distance $<3$ fingers. \\
\hline $\begin{array}{l}\text { I Vision of } \\
\text { hypopharynx }\end{array}$ & Uvula not seen. \\
\hline 2 Abnormalities & $\begin{array}{l}\text { Two of the above four physical signs were noted } \\
\text { to be abnormal preoperatively. }\end{array}$ \\
\hline$\geq 3$ Abnormalities & $\begin{array}{l}\text { Three or more of the four physical signs were } \\
\text { noted to be abnormal preoperatively. }\end{array}$ \\
\hline
\end{tabular}


TABLE III Adverse outcomes

Desaturation on induction

Any saturation $<90 \%$ by pulse oximetry or $\mathrm{PaO}_{2}<60 \mathrm{mmHg}$ in the OR before surgical incision.*

Hypertension on induction

Systolic BP $>200 \mathrm{mmHg}$ for longer than five minutes in the $\mathrm{OR}$ before surgical incision.*

Tachycardia on induction

Heart rate $>120 \mathrm{bpm}$ for longer than ten minutes in the OR before surgical incision.*

Naused and vomiting in PACU

Any complaint of nausea or active vomiting or retching in PACU.

Trachea remained intubated in PACU

Endotracheal tube in patient's trachea on arrival in PACU.

Unanticipated ICU admission (OR, PACU)

Unplanned ICU admission not anticipated before the start of the surgery.

*Excluding patients who arrived in the OR with these problems.

\section{References}

1 Caplan RA, Posner KL, Ward RJ, Cheney FW. Adverse respiratory events in anesthesia: a closed claim analysis. Anesthesiology 1990; 72: 828-33.

2 Cheney FW, Posner KL, Caplan RA. Adverse respiratory events infrequently leading to malpractice suits. A closed claims analysis. Anesthesiology 1991; 75: 932-9.

3 Benumof JL. Management of the difficult adult airway. With special emphasis on awake tracheal intubation. Anesthesiology 1991; 75: 1087-110.

4 Cobley $M$, Vaughan $R S$. Recognition and management of difficult airway problems. Br J Anaesth 1992; 68: 90-7.

5 Nolan JP. Wilson ME. An evaluation of the gum elastic bougie. Intubation times and incidence of sorer throat. Anaesthesia 1992; 47: 878-81.

6 Fisher JA, Ananthanarayan C, Edelist G. Role of the laryngeal mask in airway management (Editorial). Can $\mathbf{J}$ Anaesth 1992; 39: 1-3.

7 McCoy EP, Mirakhur RK. The levering laryngoscope. Anaesthesia 1993; 48: 516-9.

8 Dich-Nielsen JO. Nagel P. Flexible fibreoptic bronchoscopy via the laryngeal mask. Acta Anaesthesiol Scand 1993; 37: 17-9.

9 Knill $R L$. Difficult laryngoscopy made easy with a "BURP." Can J Anaesth 1993; 40: 279-82.

10 Ellis DG, Jakymec A, Kaplan RM, et al. Guided orotracheal intubation in the operating room using a lighted stylet: a comparison with direct laryngoscopic technique. Anesthesiology 1986; 64: 823-6.

11 Fox DJ, Castro TJ Jr, Rastrelli AJ. Comparison of intubation techniques in the awake patient: the Flexi-lum ${ }^{\circledR}$ surgi- cal light (lightwand) versus blind nasal approach. Anesthesiology 1987; 66: 69-71.

12 Marks RRD, Hancock $R$, Charters $P$. An analysis of laryngoscope blade shape and design: new criteria for laryngoscope evaluation. Can J Anaesth 1993; 40: 262-70.

13 Davies J, Weeks S, Crone LA, Pavlin E. Difficult intubation in the parturient. Can J Anaesth 1989; 36: 668-74.

14 King TA, Adams AP. Failed tracheal intubation. $\mathrm{Br} \mathrm{J}$ Anaesth 1990; 65: 400-14.

15 American Society of Anesthesiologists Task Force on Management of the Difficult Airway. Practice guidelines for management of the difficult airway. Anesthesiology 1993; 78: 597-602.

16 Bellhouse $C$, Doré $C$. Criteria of estimating likelihood of difficulty of endotracheal intubation with the Macintosh Laryngoscope. Anaesth Intensive Care 1988; 16: 329-37.

17 Mallampati SR, Gatt SP, Gugino LD, et al. A clinical sign to predict difficult tracheal intubation: a prospective study. Can J Anaesth 1985; 32: 429-34.

18 Davies JM, Eagle CJ. M.O.U.T.H.S. (Letter). Can J Anaesth 1991; 38: 687-8.

19 Wilson ME, Spiegelhalter D, Robertson JA, Lesser P. Predicting the difficult intubation. Br J Anaesth 1988; 61: 211-6.

20 Oates JDL, MacLeod AD, Oates PD, Pearsall FJ, Howie $J C$, Murray GD. Comparison of two methods for predicting difficult intubation. $\mathrm{Br} \mathrm{J}$ Anaesth 1991; 66: 305-9.

21 Deller A, Schreiber MN, Gramer J, Ahnefeld FW. Difficult intubation: incidence and predictability. A prospective study of 8,284 adult patients. Anesthesiology 1990 ; 73: A1054.

22 Horton WA, Fahy $L$, Charters $P$. Defining a standard intubating position using "angle finder." Br J Anaesth 1989; 62: 6-12.

23 Rose $D K$, Cohen MM. Patient problems during anaesthesia - are they related to the surgical approach? Can J Anaesth 1992; 39: (Supplement): Al11.

24 Rose DK, Cohen MM, Wigglesworth DF, Yee DA. Development of a computerized database for the study of anaesthesia care. Can J Anaesth 1992; 39: 716-23.

25 Tiret L, Desmonts JM, Hatton F, Vourch $G$. Complications associated with anaesthesia - a prospective surgey in France. Can J Anaesth 1986; 33: 336-44.

26 Fear $D W$. Failed intubation in the partiturent (Editorial). Can J Anaesth 1989; 36: 614-6.

27 Morgan $M$. Anaesthetic contribution to maternal mortality. Br J Anaesth 1987; 59: 842-55.

28 Lockhart PB, Feldbau EV, Gabel RA, Connolly SF, Silversin $J B$. Dental complications during and after tracheal intubation. J Am Dent Assoc 1986; 112: 480-3.

29 Tartell PB, Hoover LA, Friduss ME, Zuckerbraun $L$. Pharyngoesophageal intubation injuries: three case reports. Am J Otolaryngol 1990; 11: 256-60. 
30 Volpi D. Lin PT, Kuriloff DB, Kimmelman CP. Risk factors for intubation injury of the larynx. Ann Otol Rhinol Laryngol 1987; 96: 684-6.

31 Lesser $T$, Williams $G$. Laryngographic investigation of postoperative hoarseness. Clin Otolaryngol 1988; 13 : $37-42$.

32 Jones $M W$, Catling $S$, Evans E, Green DH, Green JR. Hoarseness after tracheal intubation. Anaesthesia 1992; 47 213-6.

33 Sampson $G L T$, Young JRB. Difficult tracheal intubation: a retrospective study. Anaesthesia 1987; 42: 487-90.

34 Norton $M L$, Brown $A C D$. Evaluating the patient with a difficult airway for anesthesia. Otolaryngol Clin North Am 1990; 23: 771-85.

35 Cormack RS, Lehane J. Difficult tracheal intubation in obstetrics. Anaesthesia 1984; 39: 1105-11.

36 Sutherland $A D$, Sale JP. Fibreoptic awake intubation - a method of topical anaesthesia and orotracheal intubation. Can Anaesth Soc J 1986; 33: 502-4.

37 Ovassapian A, Krejcie TC, Yelich SJ, Dykes MH. Awake fibreoptic intubation in the patient at high risk of aspiration. Br J Anaesth 1989; 62: 13-6.

38 Cahen $C R$. An aid in cases of difficult tracheal intubation (Letter). Anesthesiology 1991; 74: 197.

39 Benumof $J L$. Use of the laryngeal mask airway to facilitate fiberscope-aided tracheal intubation (Letter). Anesth Analg 1992; 74: 313-4.

40 Abou-Madi $M N$, Trop D. Pulling versus guiding: a modification of retrograde guided intubation. Can $\mathrm{J}$ Anaesth 1989; 36: 336-9.

41 Sivarajan $M$, Fink $B R$. The position and the state of the larynx during general anesthesia and muscle paralysis. Anesthesiology 1990; 72: 439-42.

42 Ovassapian A, Dykes $M H$, Golmon $M E$. A training programme for fibreoptic nasotracheal intubation. Use of model and live patients. Anaesthesia 1983; 38: 795-8.

43 Dykes $M H M$, Ovassapian A. Dissemination of fibreoptic airway endoscopy skills by means of a workshop utilizing models. Br J Anaesth 1989; 63: 595-7.

44 Rocke DA, Murray WB, Rout CC, Gouws E. Relative risk analysis of factors associated with difficult intubation in obstetric anesthesia. Anesthesiology 1992; 77: 67-73.

45 Williams KN, Carli F, Cormack RS. Unexpected, difficult laryngoscopy: a prospective survey in routine general surgery. Br J Anaesth 1991; 66: 38-44.

46 Reissell E, Orko R, Maunuksela EL, Lindgren L. Predictability of difficult laryngoscopy in patients with long-term diabetes mellitus. Anaesthesia 1990; 45: 1024-7.

47 Aiello $G$, Metcalf $I$. Anaesthetic implications of temporomandibular joint disease. Can J Anaesth 1992; 39: 610-6.

48 Nichol HC, Zuck D. Difficult laryngoscopy - the "anterior" larynx and the atlanto-occipital gap. $\mathrm{Br} J$ Anaesth 1983; 55: 141-4.
49 Chow FL, Duncan PG, Code WE, Yip RW. Can bedside neck extension predict difficult intubation? Can J Anaesth 1993; 40: A4.

50 King TA, Adams $A P$. Predicting difficult intubation. What factors influence the thyromental distance? (Letter). Anaesthesia 1992; 47: 623.

51 Frerk $C M$. Predicting difficult intubation. Anaesthesia 1991; 46: 1005-8.

52 Tham EJ, Gildersleve CD, Sanders LD, Mapleson WW, Vaughan RS. Effects of posture, phonation and observer on Mallampati classification. $\mathrm{Br} \mathrm{J}$ Anaesth 1992; 68: 32-8. 